\title{
Necessidades de saúde e direito à comunicação em tempos de midiatização
}

\section{Health needs and right to communication in times of mediatization \\ Las necesidades de salud y el derecho a la comunicación en tiempos de mediatización}

Tatiana Breder Emerich | tatiemerich@hotmail.com

Universidade Federal do Espírito Santo, Programa de Pós-Graduação em Saúde Coletiva. Vitória, Brasil.

\author{
Aline Guio Cavaca | alineguica@hotmail.com \\ Universidade Federal do Espírito Santo, Programa de Pós-Graduação em Saúde Coletiva. Vitória, Brasil.
}

Victor Gentilli | vgentilli@uol.com.br

Universidade Federal do Espírito Santo, Programa de Pós-Graduação em Comunicação e Territorialidades. Vitória, Brasil.

Adauto Emmerich | adautoemmerich@terra.com.br

Universidade Federal do Espírito Santo, Programa de Pós-Graduação em Saúde Coletiva. Vitória, Brasil.

\section{Resumo}

A contemporaneidade é marcada por uma sociedade midiatizada, na qual a mídia exerce influência sobre todas as instâncias sociais, abrangendo a saúde. Nesse cenário, incluem-se interesses, instituições e atores como partes integrantes do processo de engendramento das notícias. Sendo assim, a partir das interlocuções entre o campo da comunicação e saúde (CeS) e o campo da saúde coletiva, entende-se que o direito à comunicação é indissociável do direito à saúde e, por isso, a divulgação midiática das necessidades de saúde deveria corresponder às principais demandas populacionais inerentes a um território. Nesse sentido, este artigo objetiva discutir a (não) divulgação midiática das necessidades de saúde e refletir sobre o direito à comunicação como um direito social fundamental ao pleno exercício da cidadania e garantia do direito à saúde, no contexto de uma sociedade midiatizada.

Palavras-chave: comunicação em saúde; meios de comunicação de massa; saúde pública; Sistema Único de Saúde. 


\begin{abstract}
The contemporary world is characterized by a mediatic society in which the media has influence on all the social spheres, including the health. In this scenario, interests, institutions and actors are included as parts of the process that produces the news. From the dialogues between the field of communication \& health (C \& S) and the field of collective health, it is understood that the right to communication is inextricably linked to the right to health. Thereby, the diffusion of health needs by media should correspond to the main specific demands for health from the population of a territory. Therefore, this article aims to discuss the non-dissemination by media of the health needs and to reflect on the right to communication as a fundamental social right to full sense of citizenship and a guarantee of the right to health in the context of a mediatic society.
\end{abstract}

Keywords: health communication; mass media; public health; Sistema Único de Saúde (unified health system).

\title{
Resumen
}

La contemporaneidad es caracterizada por una sociedad mediática en que los medios de comunicación influyen en todos los ámbitos sociales, incluso en la salud. En ese contexto, se incluyen intereses, instituciones y actores que forman parte del proceso de generación de noticias. A partir de los diálogos entre el campo de la comunicación y salud (C\&S) y el campo de la salud colectiva, se entende que el derecho a la información está vinculado al derecho a la salud. En este sentido, la difusión mediática de las necesidades de la salud debe coincidir con las principales demandas específicas de la población de alguno territorio. Por lo tanto, este artículo tiene como objetivo discutir la (no) divulgación, por los medios de comunicación, de las necesidades de la salud y reflexionar sobre el derecho a la comunicación como uno derecho social fundamental a el ejercicio pleno de la ciudadanía y garantía del derecho a la salud en una sociedad mediática.

Palabras clave: comunicación en salud; medios de comunicación social; salud pública; Sistema Único de Saúde (sistema de salud unificado).

Contribuição dos autores: Os autores participaram igualmente da concepção e do desenho do estudo; da aquisição, análise ou interpretação dos dados; da revisão crítica do conteúdo intelectual e de todas as etapas de elaboração do manuscrito.

Declaração de conflito de interesses: Os autores declaram não existir conflito de interesses referente à elaboração do artigo.

Fontes de financiamento: Fapes/CNPq/MS-Decit/SESA no 10/2013 - PPSUS Programa de pesquisa para o SUS: Gestão compartilhada em saúde - PPSUS

Considerações éticas: O presente manuscrito é resultado das reflexões teóricas desenvolvidas com base na dissertação de mestrado de uma das autoras do manuscrito (Tatiana Breder Emerich), defendida em março de 2015 no Programa de PósGraduação em Saúde Coletiva da Universidade Federal do Espírito Santo (PPGSC/UFES).

Agradecimento/Contribuições adicionais: Laboratório de Projetos em Saúde Coletiva (Laprosc) da Universidade Federal do Espírito Santo (Ufes), por contribuir no debate do campo da comunicação e saúde no estado do Espírito Santo e por fomentar o desenvolvimento de projetos nesse campo de conhecimento.

Histórico do artigo: Submetido: 28.dez.2015 | Aceito: 02.out.2016 | Publicado: 12.dez.2016.

Licença CC BY-NC atribuição não comercial. Com essa licença é permitido acessar, baixar (download), copiar, imprimir, compartilhar, reutilizar e distribuir os artigos, desde que para uso não comercial e com a citação da fonte, conferindo os devidos créditos de autoria e menção à Reciis. Nesses casos, nenhuma permissão é necessária por parte dos autores ou dos editores. 


\section{Introdução}

A atualidade é marcada por uma sociedade midiatizada, uma vez que não há qualquer instância social que não receba alguma influência da mídia. Nesta sociedade, as mídias não são apenas os meios, mas, sim, complexos sistemas com realidade própria e efeito sobre o seu trabalho de enunciar realidades e auxiliar na garantia do direito à saúde ${ }^{1}$. Nesse contexto, os meios de comunicação constituem um locus privilegiado para a apreensão e expressão da complexidade das necessidades de saúde. Não obstante, as informações são tecidas pelas empresas jornalísticas, que balizam as informações ${ }^{2}$ e optam por colocar ou não em pauta as notícias sobre saúde, de acordo com interesses políticos, econômicos e mercadológicos.

O campo da comunicação e saúde (CeS) articula-se em diversas vertentes, pautado no entendimento de que o direito à comunicação é indissociável do direito à saúde³, já que o primeiro potencializa a participação e autonomia dos sujeitos, confere visibilidade às necessidades e demandas de saúde e ao Sistema Único de Saúde (SUS), contribuindo (ou não) para a efetivação do segundo direito ${ }^{4}$. As informações desse campo integram conhecimentos que analisam quais doenças e necessidades de saúde têm sido abordadas pela mídia, quais as principais demandas de saúde de um território e quais fatores estão inseridos na dinâmica de construção e veiculação das notícias de saúde.

Nesse sentido, acredita-se que há uma intensa relação entre a cobertura e o enquadramento dos temas de saúde na mídia e uma evidência ou um negligenciamento desses assuntos no cenário político e econômico ${ }^{5}$. Portanto, deve-se prezar, minimamente, estabelecer um debate público sobre necessidades de saúde pertinentes à população e garantir à sociedade uma comunicação relevante para a ampliação de sua participação cidadã nas políticas de saúde .

A partir do lugar de interlocução do campo da CeS, este artigo objetiva discutir a (não) divulgação midiática das necessidades de saúde e refletir sobre o direito à comunicação como um direito social fundamental ao pleno exercício da cidadania e garantia do direito à saúde, no contexto de uma sociedade midiatizada.

\section{Comunicação e saúde: explorando interfaces com a saúde coletiva}

A comunicação é um objeto polissêmico, foco de questões que se irradiam por múltiplas dimensões7. Por esse caráter, abrange uma vivência individual e coletiva, uma prática social e faz parte de uma experiência cotidiana que conduz à formação de opiniões mediadas pelo discurso midiático ${ }^{6}$. Além disso, constrói e confere valor à realidade, pauta a agenda de discussão, faz parte das relações que o ser humano estabelece no espaço de sua existência ${ }^{8}$, engloba saberes, práticas e processos, sendo um dos mais importantes instrumentos para se efetivar o ideal da Reforma Sanitária Brasileira, em que o sujeito deve ter condições de exercer sua autonomia quanto à saúde`.

A comunicação sobre saúde é onipresente. Jornais, revistas, televisão, rádios e internet abordam diariamente temas relacionados a ela ou à sua falta ${ }^{10}$. Por isso, a comunicação relacionada ao campo da saúde tem sido objeto de estudo e discussão de vários autores, 9, 10-16. Esse campo (comunicação e saúde) é uma episteme genuinamente brasileira e, desde a década de 1990, tem sido abordado em suas múltiplas interfaces ${ }^{6,11}$. Inclui, na contemporaneidade, estudos da comunicação midiática aplicados a outras práticas sociais e de saúde ${ }^{17}$ a partir de abordagens teórico-metodológicas interdisciplinares.

Conforme a Figura 1, esse campo engloba tanto os conhecimentos peculiares à comunicação quanto os conhecimentos da área da saúde coletiva que, tratados em conjunto e exploradas as potencialidades de cada ciência, se inter-relacionam, interagem e convergem para um amplo campo interdisciplinar. Importante esclarecer que adotamos o termo interdisciplinar, conforme proposto por Japiassú ${ }^{18}$, que considera uma 
relação de cooperação e diálogo entre as "disciplinas", sem a supremacia de uma sobre a outra e, sim, com trocas recíprocas e enriquecimento mútuo.

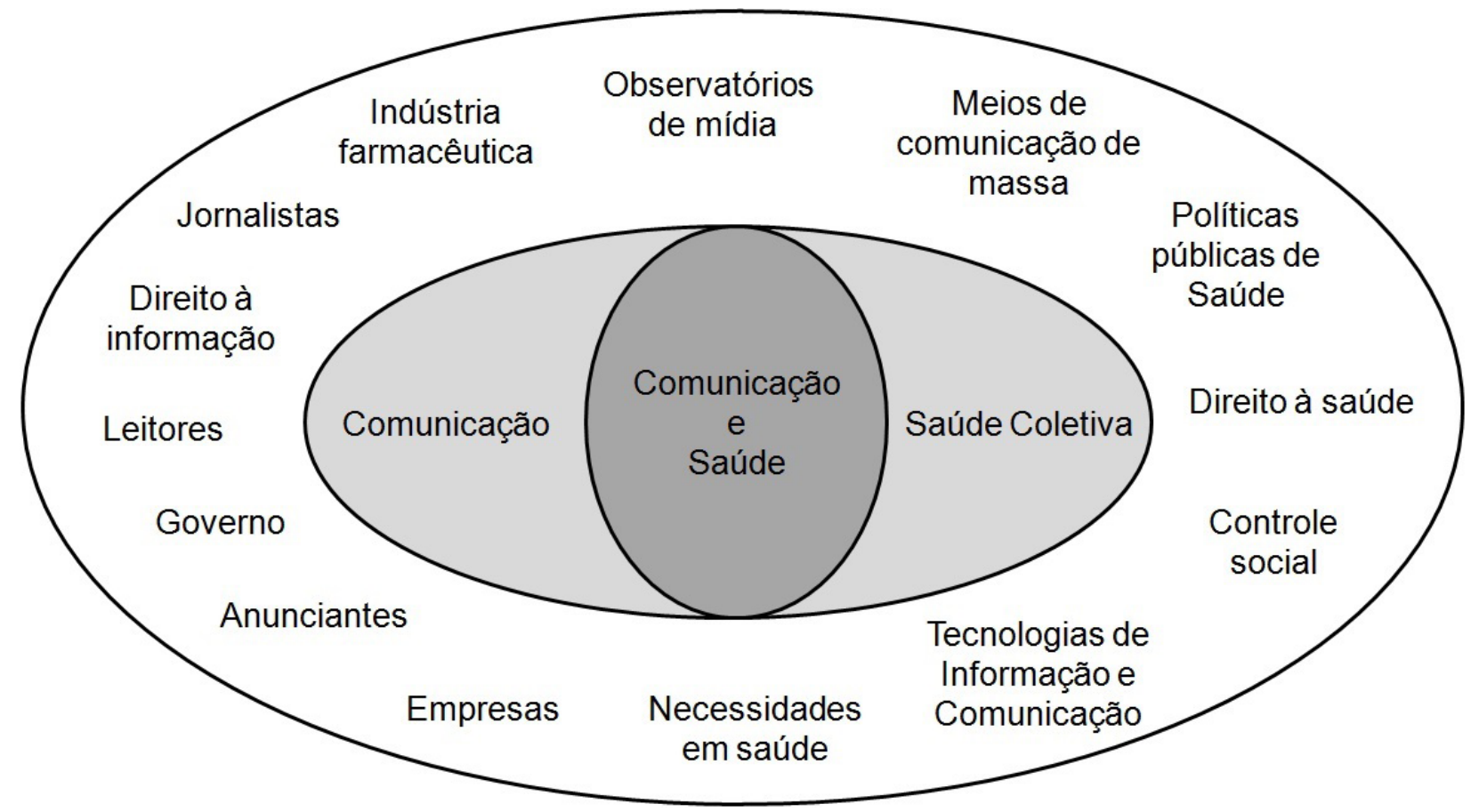

Figura 1 - O campo interdisciplinar da comunicação e saúde Fonte: Adaptado de Araújo; Cardoso (2001).

Além disso, o conectivo "e" acentua essa articulação entre os campos, concebendo o conceito de campo a partir da definição de Bourdieu ${ }^{19}$ como um espaço de relações sociais entre atores que compartilham de interesses em comum, mas no qual cada um disputa com seus próprios recursos, forças e autonomia relativa $^{20}$. Essa autonomia relativa, por sua vez, é marcada por relações de cooperação entre as distintas áreas e de supremacia dos interesses de um domínio de conhecimento em detrimento do outro. Representa um campo em formação, multidimensional, que se contrapõe às propostas reducionistas da comunicação como um conjunto de técnicas de transferência de informações a serviço da saúde ${ }^{21}$.

Institucionalmente, a CeS vem se desenvolvendo no ambiente acadêmico, por meio de linhas de pesquisa e programas de pós-graduação que trabalham para a consolidação do campo há mais de duas décadas ${ }^{21}$. A constituição de uma representação gráfica da $\mathrm{CeS}$ em uma sociedade midiatizada nos remete à inclusão de várias instituições e atores que se relacionam e compõem esse campo (entre tantos outros que não couberam no presente artigo).

O campo da CeS é suscetível, dessa forma, a intercâmbios discursivos de vários outros campos do saber, com os quais dialoga e interage ${ }^{21}$. Como consequência, a saúde coletiva insere-se como parte integrante e intercambiável de saberes e desafios fundamentais tanto à comunicação quanto à saúde. A saúde coletiva inclui saberes desenvolvidos politicamente com o objetivo de configurar a abrangência interdisciplinar e multiprofissional da saúde e romper político-epistemologicamente com a tradição da saúde pública mundial. Pode ser entendido como campo científico no qual são produzidos saberes acerca da saúde ou no campo das práticas, em que se realizam ações dentro e fora dos espaços convencionalmente reconhecidos como "setor saúde" ${ }^{22}$. Como campo científico, contribui para o estudo do fenômeno saúde-doença, enquanto processo social e no âmbito de práticas tem como objeto as necessidades sociais de saúde ${ }^{22}$ dialogando com outros 
campos de conhecimento, entre eles a CeS. Nesse sentido, a agenda da CeS agrega desafios de naturezas distintas, demandando esforços teóricos, políticos e institucionais de caráter intersetorial ${ }^{20}$.

Nesse cenário, os estudos midiáticos compõem um espectro relevante de pesquisas para a saúde coletiva, sendo o questionamento a respeito da distância entre divulgação midiática e necessidades em saúde um importante desafio epistemológico presente no contexto da sociedade midiatizada ${ }^{16}$.

\section{A sociedade midiatizada}

A definição de 'mídia', normalmente empregada para os estudos que compreendem a imprensa, o rádio, a televisão e as novas mídias, foi introduzida no Brasil a partir da tradução de publicações clássicas durante as décadas de 1970 e $1980^{23}$. Há de se ressaltar que atualmente os acontecimentos são tecidos nesse contexto de midiatização, no qual as práticas sociais são afetadas pelo modelo de comunicação que abrange a responsabilidade de influência no meio social ${ }^{1}$.

A definição de midiatização enfatiza não apenas a recepção, mas também a produção. Por isso, concentra-se em avaliar os meios de comunicação, bem como seus efeitos e, dessa forma, procura-se incluir não apenas a mediação exercida pela mídia, mas também as teorias e práticas sobre os efeitos das mídias ${ }^{23}$. De forma unificada, pode-se dizer que a mediação é apenas a primeira fase de um processo complexo que envolve a midiatização em um contexto em que os meios de comunicação de massa são importantes fontes de influência no panorama social, por poderem modificar estruturas sociais, políticas e culturais em uma sociedade midiatizada ${ }^{23}$. Nesse contexto, o acontecimento deixa de ser uma decisão apenas do ambiente jornalístico e passa a ser também resultado de grupos de interesse, instituições e atores sociais, que se tornam "produtores" de um novo trabalho de produção de sentidos ${ }^{1}$. Entre essas instituições e atores, portanto, podemos citar os próprios grupos de mídia e o ethos midiático ${ }^{3}$, as assessorias de comunicação das secretarias de saúde ${ }^{24}$, os gestores e profissionais da saúde, os conselhos de saúde e os próprios usuários do sistema de saúde brasileiro ${ }^{25}$, que por vezes se configuram como os personagens das matérias jornalísticas do campo. Esses grupos, instituições e atores muitas vezes se inclinam a um jogo de interesses mais amplo - com viés político, econômico e ideológico. Nesse sentido, o poder de decisão pode ser potencialmente deslocado dos jornalistas para os sujeitos que se tornam mais ativos no complexo contexto comunicacional e têm nele a oportunidade de serem coparticipantes para evidenciarem (ou não) suas inúmeras necessidades ${ }^{1}$.

Os pressupostos sociofilosóficos do presente artigo coadunam com o fato de que a mídia não constitui exclusivamente uma produtora dos acontecimentos, uma vez que outras instituições políticas, econômicas e sociais influenciam no processo de construção das notícias. Por isso, estudos que têm por objetivo analisar e/ou compreender a dinâmica de divulgação das notícias de saúde nos meios de comunicação deveriam incluir a potencialidade da percepção desses atores, o que tem sido uma tentativa ainda incipiente no campo da CeS. A equação comunicação e saúde, ao incluir e ter como pressupostos as lógicas midiáticas incongruentes com a lógica das necessidades de saúde, torna-se complexa, conforme pode ser evidenciado nas abordagens midiáticas das necessidades de saúde. Nesse embate se incluem lutas simbólicas e questionamentos sobre o que, para quem, com que objetivo, por que e sobre o que se fundamentam os meios de comunicação de massa.

\section{Abordagens midiáticas das necessidades de saúde}

Apesar de as necessidades de saúde não se apresentarem como um conceito fechado devido à sua complexidade, seu entendimento perpassa por ações que incidem necessariamente nos determinantes e condicionantes do processo saúde-doença ${ }^{26}$. Utilizando como referencial o modelo de Determinantes 
Sociais da Saúde (DSS), proposto por Dahlgren e Whitehead ${ }^{27}$, teremos no primeiro nível o estilo de vida dos indivíduos que é fortemente influenciado pelas normas culturais ditadas pela mídia. Para atuar de forma efetiva sobre esse primeiro nível de DSS, fazem-se necessárias políticas públicas coerentes com as necessidades de saúde, que tenham como objeto de trabalho as necessidades de grupos populacionais de diferentes classes sociais de um território, além de uma atuação da mídia que contribua nesse processo.

De forma sistemática, as necessidades de saúde podem ser traduzidas como: necessidades da presença do Estado, como responsável pela garantia dos serviços e direitos universais para promoverem a saúde da população; necessidades de reprodução social, que incluem os fatores condicionantes e determinantes da saúde; e a necessidade de participação política, capaz de suscitar o embate entre diferentes classes sociais da sociedade civil, fazendo os direitos prevalecerem sobre os interesses ${ }^{28,29}$.

Analisado sobre o prisma da vertente marxista, o conceito de necessidade de saúde engloba os diferentes padrões do processo saúde-doença, a partir das relações que os seres humanos estabelecem entre si para reproduzir a vida social, com sua gênese nas condições materiais da vida cotidiana. Dessa forma, no campo da saúde coletiva, é essencial considerar as diferentes reproduções sociais de distintos grupos, pois essas desigualdades incidirão sobre os padrões de saúde-doença das populações, originando também diferentes necessidades de saúde ${ }^{26}$.

A saúde coletiva precisa produzir conhecimento, responder questionamentos e mediar processos visando equacionar dificuldades. Na solução desses problemas de saúde dos indivíduos podem estar implícitos embates entre necessidades, trabalhadores de saúde, gestores, políticas públicas, autores dos programas, órgãos financiadores ${ }^{26}$ e o discurso da própria mídia, como instrumento de visibilidade ou invisibilidade midiática da saúde ${ }^{6}$. Por isso, a inclusão da mídia no debate das necessidades de saúde torna-se fundamental e então é preciso perguntar: quais têm sido as necessidades de saúde veiculadas na mídia? Será que existem necessidades de saúde negligenciadas?

Para responder a essas questões, é necessário que contextualizemos a sociedade midiatizada, na qual as instituições e os atores atuam como coparticipantes da divulgação de notícias. Entre as empresas e os grupos de interesse envolvidos na divulgação midiática da saúde, incluem-se os laboratórios farmacêuticos multinacionais, as indústrias alimentícias, os fabricantes de aparelhos de ginásticas, os hospitais que querem encher seus leitos e os editores que desejam vender seus livros ${ }^{10}$. Sendo assim, apesar de os grupos de interesse muitas vezes terem informações pertinentes para oferecer, essas informações precisam ser avaliadas, já que há interesses particulares de mercado implicitamente embutidos ${ }^{10}$.

Paralelamente, há de se considerar os engendramentos envolvidos na seleção das notícias de saúde e os critérios de noticiabilidade do jornalismo. Presentes na lógica de indústria de notícias, os critérios do que é noticiável correspondem aos atributos dos acontecimentos que fazem com que eles se transformem em notícias, tais como: novidade, proximidade geográfica, proeminência dos atores envolvidos, negativismo, amplitude, atualidade, impacto e/ou consequência, ineditismo, dramaticidade, impacto, descobertas e/ou invenções, entre outros ${ }^{29}$.

Em adição, Tabakman ${ }^{10}$ retrata aspectos importantes relacionados à "saúde na mídia" que vão desde o espaço ocupado até as fontes às quais os jornalistas recorrem, as interfaces que permeiam as relações entre profissionais da saúde (na sua maioria representados pela figura do médico) e jornalistas, as estratégias utilizadas na divulgação das notícias, os temas prioritários que ocupam a pauta jornalística, o impacto e a influência das informações veiculadas. A mesma autora define "notícia em saúde" como: "Não apenas o que querem divulgar as fontes oficiais. É talvez tudo que publica um jornalismo sensível aos interesses e às necessidades das pessoas que de outro modo a audiência não saberia" ${ }^{10}$. Dessa maneira, assim como a visibilidade pode contribuir para o reconhecimento das necessidades de saúde, a invisibilidade pode levar à negligência. Sendo assim, diante do (re)conhecimento público de um determinado agravo através dos meios de comunicação, por exemplo, é mais provável que ele seja incluído nas bases de dados, que se 
transforme em objeto de pesquisa e apareça nas estatísticas oficiais, motivando, dessa forma, a discussão de políticas públicas sobre suas questões ${ }^{30}$. É evidente que a visibilidade midiática por si só não garante o cuidado. Na posição oposta, a hipervisibilidade pode ser negativa e geradora de produtos midiáticos muitas vezes alarmistas e prejudicais ${ }^{30}$.

Os critérios jornalísticos muitas vezes entram em conflito com os interesses de cientistas e das próprias necessidades de saúde ${ }^{31}$. Esses pressupostos sugerem que algumas temáticas de saúde tendem a ser evidenciadas pela mídia, enquanto outras podem estar sendo negligenciadas, seja pela ausência de notícias relacionadas às necessidades específicas, seja pelo enfoque dado a determinados fatos. Dessa forma, vejamos alguns exemplos dessa discrepância e de seus resultados.

Em primeiro lugar, desde a década de 1990, estudos já evidenciavam uma discrepância entre a divulgação midiática de algumas mazelas como as epidemias de doença meningocócica, que receberam ampla cobertura midiática, em oposição à epidemia de sarampo, que foi pouco enfatizada. Uma das explicações é que a primeira é uma ameaça a todos os estratos sociais, enquanto a segunda só apresenta uma ameaça real aos segmentos mais pobres, desassistidos e que não dispõem de voz na cena política ${ }^{32}$.

Outro exemplo é um editorial sobre H1N1 que mostrou a discrepância entre o que é divulgado pela mídia e temido pela população e as reais ameaças de saúde coletiva ${ }^{33}$. Durante o período de treze dias no ano de 2009, houve 31 mortes causadas pela influenza H1N1 e 63.066 mortes causadas pela tuberculose. Em contrapartida, o número de notícias sobre a Influenza H1N1 foi de 253.442, enquanto as de tuberculose totalizaram apenas 6.501. A partir desse contexto, o cálculo de um índice 'morte-notícia' para a H1N1 foi de 8.176 e para a tuberculose foi de $0.1^{33}$.

O questionamento a um assessor de imprensa de uma revista proeminente no Brasil sobre a necessidade de conseguir um espaço para divulgar resultados de uma pesquisa sobre a hanseníase também evidencia essa discrepância, já que a jornalista que o questionou obteve a seguinte resposta: "Meu leitor morre de ataque cardíaco, não de hanseníase"34.

Esse distanciamento também pode ser revelado a partir da investigação da relação entre a capacidade de agendamento da mídia e os níveis de financiamento de doenças como malária, HIV/aids, tuberculose, diarreia, pneumonia infantil e sarampo, de 1981 a 2008, revela que as doenças negligenciadas infantis de baixo financiamento (Lower Funded Diseases) são apresentadas de forma diferenciada na mídia quando comparadas com as de alto financiamento (Global Fund Diseases), tanto quantitativamente (291.865 notícias contra 1.344.150, respectivamente) quanto qualitativamente 5 .

Nesse mesmo raciocínio, a descrição da cobertura internacional de doenças negligenciadas, principalmente a tripanossomíase africana, a leishmaniose e a doença de Chagas, de janeiro de 2003 a junho de 2007, evidenciam que os jornalistas concordam que as doenças negligenciadas são assuntos importantes que não são adequadamente cobertos, com a ressalva de que as notícias devem ter alta noticiabilidade para serem divulgadas. A propósito, os poucos jornalistas que as cobriram o fizeram por motivação pessoal e, não, por elas serem pautas definidas pelo jornal ${ }^{35}$.

$\mathrm{Na}$ contramão da invisibilidade midiática, a dengue encontra sempre lugar cativo na imprensa ${ }^{36}$, tornando a experiência da doença mais comum para a população pela ampla divulgação do assunto. Além disso, costuma ser priorizada pela imprevisibilidade, novidade, peso social, proximidade geográfica, impacto sobre o público e perspectivas de evolução do acontecimento; praticamente todos os critérios que norteiam a noticiabilidade de um fato ${ }^{37}$.

Os exemplos citados relacionados à divulgação da saúde nos meios de comunicação nos remetem à compreensão de conceitos-chave: as "Doenças Midiáticas" ${ }^{10}$, as "Doenças Negligenciadas” 38 e as "Doenças Midiaticamente Negligenciadas" - DMN ${ }^{16}$.

Doenças midiáticas são patologias causadas pelos meios de comunicação de massa. Um exemplo são os transtornos alimentares como a anorexia ou bulimia, já que alguns as consideram doenças advindas 
da hiperdivulgação e hipervalorização do corpo vinculado à estética corporal e baixos níveis de gordura pelas revistas de moda e beleza ${ }^{10}$. De outra forma, também podem ser consideradas midiáticas as doenças hiperdivulgadas pela mídia, como a aids ${ }^{39}$ e a dengue ${ }^{36}$. A propósito, sugere-se também o conceito de epidemia midiática ${ }^{40}$, que corresponde a uma epidemia gerada pela excessiva cobertura jornalística de determinada doença ${ }^{38}$.

As doenças negligenciadas são aquelas que, além de prevalecerem em condições de pobreza, contribuem para manutenção das desigualdades ${ }^{38}$. Nelas estão incluídas a dengue, a doença de Chagas, a esquistossomose, a hanseníase, a leishmaniose, a malária e a tuberculose ${ }^{38}$, entre outras, que, desde 2003 , têm sido foco de editais de prioridades de pesquisa do Ministério da Saúde.

Essas doenças padecem de muitas desatenções técnicas: necessidade de mais pesquisas; necessidade de investimento de recursos financeiros, fármacos, tecnologias de diagnóstico e iniciativas políticas (educação, cultura, ampliação do acesso aos serviços); necessidade de melhor enfoque midiático, visto que, no Brasil, não há uma política de comunicação específica para esse conjunto de agravos. Sendo assim, a comunicação torna-se uma comunicação negligenciada, que é inadequada às necessidades da população ${ }^{30}$. A dengue poderia ser considerada uma exceção, já que é uma doença que tem sido muito evidenciada pela mídia ${ }^{36}$. Entretanto, há de se questionar se a cobertura da dengue pelos meios de comunicação tem sido satisfatória, levando em conta os pontos de vista técnico, político-cultural e social. Por isso, essas abordagens não podem ser consideradas exitosas no que se referem às estratégias de comunicação para o combate a essa doença.

Ademais, o direito à comunicação em saúde se relaciona com o direito à saúde, por exemplo, no que se refere em pautar doenças raras ${ }^{41}$ que, ao se tornarem midiatizadas, passam a ser discutidas e requeridas como direito na sociedade. Nesse sentido, acredita-se que a inclusão no escopo midiático de algumas necessidades de saúde como doenças com tratamentos inovadores e de alto custo, tende a ser um importante instrumento para debate dessas necessidades nas esferas políticas, sociais e econômicas.

A intensificação do elo entre o direito à comunicação e o direito à saúde, nos remete às $\mathrm{DMN}^{16}$, que correspondem às doenças que possuem pequena ou inoperante exposição midiática frente à sua grande relevância social e em saúde ${ }^{16}$. São doenças que evidenciam o distanciamento entre as lógicas que definem a divulgação de determinado assunto (critérios de noticiabilidade) aliado às lógicas do mercado da atenção ${ }^{42}$ e às moléstias que prevalecem em condições de pobreza e que não possuem atrativos à divulgação e à atenção midiática ${ }^{16}$. Ao conceber a mídia como um lugar privilegiado de visibilidade pública, construção de sentidos e legitimidade, a noticiabilidade dessas doenças/temáticas pode evidenciar quais necessidades de saúde de determinado grupo populacional têm sido negligenciadas.

Nessa perspectiva, a inclusão de algumas necessidades de saúde esquecidas ou desprezadas tende a ser um importante instrumento para debate dessas necessidades nas esferas políticas, sociais e econômicas, pois resulta no alcance das informações de saúde pela população e, dessa forma, pode contribuir para a garantia do direito à comunicação e, consequentemente, para a garantia do direito à saúde.

\section{A importância do direito à comunicação em saúde}

Ao longo das práticas comunicativas modernas, o direito à comunicação tem sido considerado um direito-síntese dos direitos humanos ${ }^{43} \mathrm{e}$ um campo mediador que abre portas para todos os demais direitos. Sendo assim, a informação é indispensável à construção da cidadania e inerente à atividade jornalística moderna e contemporânea, inserida em uma sociedade midiatizada. Ademais, o jornalismo é uma das formas de expressão do direito social, apesar de não ser a única. O cidadão tem o direito de ser provido das informações necessárias para o seu dia a dia, e as informações sobre saúde devem ser concebidas nessa dimensãoº ${ }^{2}$. Por conseguinte, a saúde, ao ser definida por tratados internacionais e constituições de Estados como um direito de cidadania ativa o direito à comunicação em saúde. 
O acesso à informação em saúde de qualidade, portanto, atua em prol da coletividade, contribuindo para o direito à saúde ${ }^{44}$. Não obstante, é importante ressaltar que o direito à comunicação em saúde envolve também a garantia de que sejam disseminados conteúdos de qualidade e condizentes com as necessidades e demandas de saúde e promovam uma mobilização em defesa do SUS, o que nem sempre tem ocorrido, conforme demonstrado ao longo deste artigo ${ }^{4}$.

O direito à comunicação abrange não só o acesso às informações como também a (falta de) expressão dos cidadãos, das instituições e dos grupos sociais, inclusive para explicitar suas necessidades de saúde. Como conceito, deveria servir como referência e contraponto à falta de diversidade e pluralidade que caracteriza os meios de comunicação brasileiros, diversificando positivamente a escolha dos temas, as abordagens e as vozes selecionadas para falar sobre a saúde no país ${ }^{3}$.

A clara compreensão do direito à saúde passa pela definição desses termos isoladamente. $\mathrm{O}$ conceito de saúde adotado pela Organização Mundial de Saúde pressupõe o completo bem-estar físico, mental e social. Já o de direito fundamenta-se em regras de comportamento humano em sociedade, limitando condutas nocivas à vida social. Logo, a saúde definida como um direito precisa incluir aspectos sociais e individuais ${ }^{45}$.

Não obstante, o direito à saúde confere à informação jornalística sobre saúde um valor de cidadania que ultrapassa os clássicos valores pedagógicos tradicionais de campanhas sanitaristas e de medicina preventiva, tornando-se objeto de crítica, vigilância e efetivação desse direito ${ }^{46}$. Os jornais constituem instituições sociais importantes na produção de informações de caráter público, sendo um instrumento mediador das informações e, ao mesmo tempo, representante dos cidadãos ${ }^{2}$. Por conseguinte, o direito à informação pública não pode ser desvinculado do direito à cidadania, já que, ao contrário, encontram-se intrinsecamente ligados.

É evidente que, para se ter acesso ao poder público, "o cidadão precisa ter assegurado o direito à informação pública”. Em consonância, o direito à comunicação assegura não apenas a cidadania, mas também outros dividendos, como levar ao conhecimento do público informações importantes à saúde ${ }^{32}$.

Entretanto, é preciso destacar que não bastam os meios de comunicação exercer um papel "informativo". Por isso, a garantia da qualidade da comunicação na área da saúde depende da disposição dos meios de comunicação de se posicionarem em defesa dos interesses da coletividade, o que inclui abordagens midiáticas que devem enaltecer o sistema público de saúde. Enquanto a saúde for tratada pela mídia como um mercado de produtos e serviços à disposição de uma sociedade consumista, a comunicação da saúde estará condicionada em evidenciar o fracasso do SUS em prol do mercado privado da saúde ${ }^{4}$ e no qual mazelas das classes inferiores/minoritárias são desprezadas. Dessa forma, é preciso que jornalistas se empenhem em trazer ao espaço público as informações de interesse coletivo, assim como é necessário que a coletividade se preocupe em exercer o controle social para cobrar que a mídia traduza, de forma correta e com qualidade, informações sobre as necessidades de saúde da população e o SUS ${ }^{32}$.

O empenho por parte dos jornalistas traduz-se em profissionalização e apreensão de conhecimentos mínimos sobre saúde para uma atuação com excelência ${ }^{32,10}$. Além disso, requer que a função do jornalismo em saúde transcenda ao trivial, visto que ele tem a missão de obter e fornecer informações verdadeiras que possibilitem as pessoas tomarem decisões e formarem uma opinião com liberdade genuína ${ }^{10}$.

Sem as informações em saúde, os usuários não são capazes de lutar pelos seus direitos, o que dificulta o exercício da cidadania. A comunicação propicia certa autonomia aos cidadãos, colocando-os como atores ativos, capazes de lutar politicamente pelas necessidades de saúde de sua comunidade contribuindo para a garantia do direito à saúde.

Por isso, retomando a Figura 1, que demonstra a abrangência do campo da CeS, observamos que os estudos nesse campo precisam incluir no debate as assessorias de comunicação, gestores e profissionais de saúde, jornalistas e os próprios conselhos de saúde, entre outros, pois são atores e instituições importantes na formação de conhecimentos nessa área ${ }^{3,24,25}$. 


\section{Considerações finais}

A abordagem midiática das necessidades de saúde pelos meios de comunicação de massa privilegia alguns temas em detrimento de outros e se utiliza de um enquadramento permeado por pressupostos da política editorial jornalística, que não necessariamente correspondem à lógica das necessidades de saúde da população.

A invisibilidade midiática de algumas temáticas e doenças na mídia não contribuem para a garantia do direito à comunicação, tornando-se um obstáculo a esse direito. De modo semelhante, a não divulgação de algumas necessidades de saúde tende a subdimensionar as discussões políticas, econômicas e sociais desses problemas, constituindo-se um entrave à cidadania e à garantia do direito à saúde.

Apesar da íntima interface de articulação da CeS com a saúde coletiva, a potencialidade dessas relações deve ser melhor explorada. Faz-se necessário uma dinâmica midiática que seja coerente com o destaque das principais necessidades de saúde da população e que potencialize a comunicação como propulsora do direito à saúde.

\section{Referências}

1. Fausto-Neto A. Midiatização da enfermidade de Lula: sentidos em circulação em torno de um corpo significante. In: Janotti Junior J, Mattos AM, Jacks N, organizadores. Mediação e midiatização. Brasília: Compós; 2012.

2. Gentilli V. Democracia de massas:jornalismo e cidadania: estudo sobre as sociedades contemporâneas e o direito dos cidadãos à informação. Porto Alegre: EDIPUCRS; 2005.

3. Guareschi P. O direito humano à comunicação: pela democratização da mídia. Petrópolis: Vozes; 2013.

4. Caron $E$, Lefèvre $F$, Lefêvre AMC. In the final analysis, are we a consumer society or not? Implications for health. CiêncSaúde Coletiva[Internet]. 2015 jan. [citado 2016 out. 17]; 20(1): 145-53. Disponível em: http://www.scielosp.org/scielo.php?script=sci arttext\&pid=S1413-81232015000100145.

5. Hudacek DL, Kuruvilla S, Kim N, Semrau S, Thea D, Qazi S, et al. Analyzing media coverage of the Global Fund Disease compared with Lower Funded Diseases (childhood pneumonia, diarrhea and measles). PLoSONE [Internet]. 2011 Jun [cited 2016 Oct 18];6 (6):1-9. Disponível em: http://journals. plos.org/plosone/article?id=10.1371/journal.pone.0020438.

6. $\quad$ Araújo IS, Cardoso JM. Comunicação e saúde. 20 ed. Rio de Janeiro: Fiocruz; 2007.

7. Teixeira RR, Cyrino AP. As ciências sociais, a comunicação e a saúde. Ciênc, saúde coletiva [Internet]. 2003 [citado 2016 out. 18];8(1):151-72. Disponível em: http://www.scielo.br/scielo.php?script=sci artte xt\&pid=S1413-81232003000100012.

8. Guareschi PA. Mídia e democracia: o quarto versus o quinto poder. Revista Debates [Internet]. 2007 [citado 2016 out. 18];1(1):6-25. Disponível em: http://seer.ufrgs.br/index.php/debates/article/ view/2505/1286.

9. Xavier C. Mídia e saúde, saúde na mídia. In: Santos A, organizadora. Caderno mídia e saúde pública. Belo Horizonte: Escola de Saúde Pública/Funed; 2006. p. 43-55.

10. Tabakman R. A saúde na mídia: medicina para jornalistas, jornalismo para médicos. São Paulo: Summus Editorial; 2013.

11. Pitta AR, organizador. Saúde \&comunicação: visibilidades e silêncios. São Paulo: Hucitec/Abrasco; 1995.

12. Cavaca AG, Gentilli V, Zandonade E, Cortellete Júnior M, Emerich A. A saúde bucal na mídia impressa: análise das matérias jornalísticas nos anos de 2004-2009. Ciênc. saúde coletiva [Internet]. 2012 maio [citado 2016 out. 18];17(5):1333-45. Disponível em: http://www.scielosp.org/scielo.php?script=sci artte xt\&pid=S1413-81232012000500027.

13. Natansohn G. Comunicação e saúde: interfaces e diálogos possíveis. Eptic [Internet]. 2004 [citado 2016 out. 18];6(2):38-52. Disponível em: http://www.seer.ufs.br/index.php/eptic/article/view/411/538. 
14. Castiel LD, Vasconcellos-Silva PR. Precariedades do excesso: informação e comunicação em saúde coletiva. Rio de Janeiro: Fiocruz; 2006.

15. Oliveira VC. A comunicação midiática e o Sistema Único de Saúde. Interface Comunicação, Saúde, Educação [Internet].2000 ago. [citato 2016 out. 18];4(7):71-80. Disponível em: http://www.scielo.br/ pdf/icse/v4n7/06.pdf.

16. Cavaca AG, Vasconcellos-Silva PR. Doenças midiaticamente negligenciadas: uma aproximação teórica. Interface Comunicação, Saúde, Educação [Internet]. 2015 [citado 2016 out. 18];19 (52):83-94. Disponível em: http://www.scielo.br/scielo.php?pid=S1414-32832015000100083\&script=sci abstract.

17. Ribeiro APG. Antônio Fausto Neto: saúde em uma sociedade midiatizada. Revista ECO-Pós [Internet] 2007 jan.-jul. [citado 2016 out. 18];10(1):198-205. Disponível em: https://revistas.ufrj.br/index.php/ eco pos/article/view/1049/989.

18. Japiassu H. Interdisciplinaridade e patologia do saber.Rio de Janeiro: Imago; 1976.

19. Bourdieu P. O poder simbólico. Rio de Janeiro: Bertrand Brasil; 1989.

20. Cardoso JM, Araújo IS. Comunicação e saúde. In: Pereira IB, Lima JCF, editores. Dicionário da educação profissional em saúde. 2 ed. Rio de Janeiro: Fiocruz; 2009.

21. Torres MM. O campo da comunicação e saúde no Brasil: mapeamento dos espaços de discussão e reflexão acadêmica [dissertação online]. Rio de Janeiro: Instituto de Comunicação e Informação Científica e Tecnológica em Saúde, Fundação Oswaldo Cruz, Rio de Janeiro; 2012. [citado 2016 out. 18]. Disponível em: http://www.arca.fiocruz.br/handle/icict/6191.

22. Paim JS, Almeida Filho N. Saúde coletiva: uma "nova saúde pública" ou campo aberto a novos paradigmas? Revista deSaúde Pública [Internet] 1998 [citado 2016 out. 2016];32(4):299-316. Disponível em: http://www.revistas.usp.br/rsp/article/view/24383.

23. Janotti Junior J, Mattos AM, Jacks, N, organizadores. Mediação e midiatização. Salvador: EDUFBA; Brasília: Compós; 2012.

24. Martinuzzo J. A. Seis questões fundamentais da assessoria de imprensa estratégica em rede. Rio de Janeiro: Mauad X; 2013.

25. Romeyer H. La santé dans l'espace public. Rennes: Presses de l'EHESP; 2010. (Communication santé social).

26. Campos CMS, Bataiero MO. Necessidades de saúde: uma análise da produção científica brasileira de 1990 a 2004. Interface Comunicação, Saúde, Educação [Internet] 2007set.-dez. [citado 2016 out. 2016];11(23):605-618. Disponível em: http://www.scielo.br/scielo.php?script=sci arttext\&pid $=\mathrm{S} 1414-32832007000300014$

27. Buss PM, Pellegrini-Filho A. A saúde e seus determinantes sociais. Physis: Revista de Saúde Coletiva [Internet]. 2007 [citado 2016 out. 2016];17(1):77-93. Disponível em: http://www.scielo.br/pdf/physis/ v17n1/v17n1a06.pdf

28. Campos CMS, Mishima SM. Necessidades de saúde pela voz da sociedade civil e do Estado. Cad. Saúde Pública [Internet] 2005 jul.-ago [citado 2016 out. 18]; 21(4):1260-8. Disponível em: http://www.scielo. br/scielo.php?script=sci arttext\&pid=S0102-311X2005000400029.

29. Silva G, Silva MP, Fernandes ML, organizadores.Critérios de noticiabilidade: problemas conceituais e aplicações. Florianópolis: Insular; 2014.

30. Araújo IS, Moreira ADL, Aguiar R. Doenças negligenciadas, comunicação negligenciada. Apontamentos por uma pauta política e de pesquisa. Reciis:Rev Eletr Comun Inf Inov Saúde[Internet] 2013 fev. [citado 2016 out. 18];6(4):Supl. Disponível em: http://www.arca.fiocruz.br/handle/icict/9660.

31. Epstein I. Comunicação de massa para a saúde: esboço de uma agenda midiática. Revista Latinoamericana de Ciencias de la Comunicación [Internet] 2008 [citado 2016 out. 18];5(8-9):132-42. Disponível em: http://www.eca.usp.br/associa/alaic/revista/r8-9/art 06.pdf

32. Barata RCB. Saúde e direito à informação. Cad. Saúde Pública [Internet]1990out.-dez. [citado em 2016 out. 18];6(4):385-99. Disponível em: http://www.scielo.br/scielo.php?script=sci arttext\&pid=S0102311X1990000400003.

33. Allebeck P. Contributing to an important debate or increasing the news/death ratio? Eur J Public Health [Internet]2010 [cited 2016 Oct 18];20(5): 483-85. Disponível em: http://eurpub.oxfordjournals.org/ content/20/5/483 
34. Guimarães C. A realidade que não cabe no jornal. Observatório da Imprensa. 2014 abr. 29; Edição 796. [citado2015 nov 12]. Disponível em: http://observatoriodaimprensa.com.br/imprensa-em-questao/ ed796 a realidade que nao cabe no jornal

35. Balasegaram M, Balasegaram S, Malvy D, Millet P. Neglected diseases in the news: acontent analysis of recent international media coverage focussing on Leishmaniasis andTrypanosomiasis. PLoSNeg|TropDis[Internet] 2008[cited 2016 Oct 18];2(5):1-5.Disponível em: http://journals.plos.org/ plosntds/article?id=10.1371/journal.pntd.0000234.

36. Villela EFM, Natal D. Representações sobre a dengue na comunicação midiática: há preocupação com a competência informacional? Reciis: Rev Eletr Comun Inf Inov Saúde [Internet] 2013 mar. [citado 2016 out. 18];7(1). Disponível em: http://www.reciis.icict.fiocruz.br/index.php/reciis/article/view/596.

37. Ferraz LMR, Gomes IMAM. A construção discursiva sobre a dengue na mídia. Rev Bras Epidemiol [Internet]. 2012 mar. [citado 2016 out. 18];15(1):63-74. Disponível em: http://www.scielo.br/scielo. php?script $=$ sci arttext\&pid=S1415-790X2012000100006.

38. Brasil. Ministério da Saúde. Secretaria de Ciência, Tecnologia e Insumos Estratégicos. Departamento de Ciência e Tecnologia. Doenças negligenciadas: estratégias do Ministério da Saúde. R Saúde Pública [Internet] 2010 [citado 2016 out. 18];44(1):200-202. Disponível em: http://www.scielo.br/pdf/rsp/ v44n1/23.pdf.

39. Spink MJP, Medrado B, Menegon VM, Lima H. A construção da Aids-notícia. Cad Saúde Pública [Internet]2001 jul.-ago. [citado 2016 out. 18];17(4):851-862.Disponível em: http://www.scielo.br/scielo. php?script=sci arttext\&pid=S0102-311X2001000400019.

40. Malinverni C, Cuenca AMB, Brigagão JIM. Epidemia midiática: produção de sentidos e configuração social da febre amarela na cobertura jornalística, 2007-2008. PHYSIS: Revista Saúde Coletiva [Internet] 2012 [citado 2016 out. 18];22(3):853-72. Disponível em: http://www.scielo.br/scielo.php?script=sci artt ext\&pid=S0103-73312012000300002

41. Dominguez B. 13 milhões de raros: pessoas afetadas com doenças complexas e pouco conhecidas se mobilizam para viabilizar políticas públicas e combater preconceitos. Radis: Comun Saúde [Internet]. 2015 fev. [citado 2016 out. 18];(149)10-7. Disponível em: http://www6.ensp.fiocruz.br/radis/sites/ default/files/radis 149 site.pdf.

42. Cavaca AG, Vasconcellos-Silva PR. O mercado da atenção e as doenças midiaticamente negligenciadas. R BrasPesq saúde[Internet]. 2014[citado 2016 out. 18];15(4)4-5. Disponível em: http://periodicos.ufes. br/RBPS/article/view/7592/5256

43. Araújo EA. Informação, cidadania e sociedade no Brasil. Inf\&Soc: Est. [Internet]. 1992 jan./dez. [citado 2016 out. 18];2(1):42-9. Disponível em: http://www.ies.ufpb.br/ojs/index.php/ies/article/view/43/1350.

44. Cavalcante RB, Pessalacia JDR, Pinheiro MMK, Watanabe YJA, Magalhães-Silva TI, José da Silva C. Direito à informação em saúde no Brasil: em busca da legitimação. $R$ EnfermCent Oeste Mineiro [Internet].2014 jan./abr. [citado 2016 out. 18];4(1):1004-18. Disponível em: http://www.seer.ufsj.edu. br/index.php/recom/article/view/598/575.

45. Dallari SG. The right to health. R Saúde Públ [Internet]. 1988 fev. [citado 2016 out. 18];22(1): 57-63. Disponível em: http://www.scielo.br/scielo.php?script=sci arttext\&pid=S0034-89101988000100008

46. Kucinski B. Jornalismo, saúde e cidadania. Interface ComunSaúde Educ [Internet]2000 fev. [citado 2016 out. 18];4(6):181-86. Disponível em: http://www.scielo.br/scielo.php?script=sci arttext\&pid $=$ S1414-32832000000100025. 